\title{
Quantitative determinations and imaging in different structures of buried human bones from the XVIII-XIXth centuries by energy dispersive X-ray fluorescence - Postmortem evaluation
}

\author{
D. Guimarães ${ }^{\text {a,b,*, }}$ A.A. Dias ${ }^{\text {c }}$, M. Carvalho ${ }^{c}$, M.L. Carvalho ${ }^{c}$, J.P. Santos ${ }^{c}$, F.R. Henriques ${ }^{\text {d }}$, \\ F. Curate ${ }^{\mathrm{e}, \mathrm{f}}, \mathrm{S}$. Pessanha ${ }^{\mathrm{c}}$ \\ a Laboratory of Inorganic and Nuclear Chemistry, Wadsworth Center, New York State Department of Health, P.0. Box 509, Albany, NY 12201-0509, USA \\ ${ }^{\mathrm{b}}$ Department of Environmental Health Sciences, School of Public Health, the University at Albany, P.O. Box 509, Albany, NY 12201-0509, USA \\ ${ }^{\mathrm{c}}$ LIBPhys-UNL, Laboratório de Instrumentação, Engenharia Biomédica e Física da Radiação and Departamento de Física da Faculdade de Ciências e Tec- \\ nologia, Universidade Nova de Lisboa, 2829-516 Caparica, Portugal \\ ${ }^{\mathrm{d}}$ Museums Division and Local History, City Hall Almada, Portugal \\ ${ }^{\text {e }}$ Research Centre for Anthropology and Health, University of Coimbra, Portugal \\ ${ }^{\mathrm{f}}$ Interdisciplinary Center for Archaeology and Evolution of Human Behavior, University of Algarve, Portugal
}

\section{A R T I C L E I N F O}

\section{Article history:}

Received 22 February 2016

Received in revised form

13 April 2016

Accepted 13 April 2016

Available online 26 April 2016

Keywords:

Human bone

Elemental concentration, Micro-X Ray

fluorescence

Triaxial EDXRF

\begin{abstract}
A B S T R A C T
In this work, a non-commercial triaxial geometry energy dispersive X-ray Fluorescence (EDXRF) setup and a benchtop $\mu$-XRF system were used to identify postmortem contamination in buried bones. For two of the individuals, unusually high concentrations of $\mathrm{Cu}$ and $\mathrm{Pb}$, but also $\mathrm{Zn}$ (in one individual) were observed. The pigments of the burial shroud coverings have been identified as the source of contamination.

Accurate and precise quantitative results were obtained by nondestructive process using fundamental parameters method taking into account the matrix absorption effects.

A total of 30 bones from 13 individuals, buried between the mid-XVIIIth to early XIXth centuries, were analyzed to study the elemental composition and elemental distribution. The bones were collected from a church in Almada (Portugal), called Ermida do Espírito Santo, located near the Tagus River and at the sea neighbourhood.

The triaxial geometry setup was used to quantify $\mathrm{Ca}, \mathrm{Fe}, \mathrm{Cu}, \mathrm{Zn}, \mathrm{Br}, \mathrm{Sr}$ and $\mathrm{Pb}$ of powder pressed bone pellets ( $n=9$ for each bone). Cluster analysis was performed considering the elemental concentrations for the different bones. There was a clear association between some bones regarding $\mathrm{Fe}, \mathrm{Cu}, \mathrm{Zn}, \mathrm{Br}$ and $\mathrm{Pb}$ content but not a categorization between cortical and trabecular bones. The elemental distribution of $\mathrm{Cu}$, $\mathrm{Zn}$ and $\mathrm{Pb}$ were assessed by the benchtop $\mu$-analysis, the M4 Tornado, based on a polycapillary system which provides multi-elemental $2 \mathrm{D}$ maps. The results showed that contamination was mostly on the surface of the bone confirming that it was related to the burial shroud covering the individuals.
\end{abstract}

(c) 2016 Elsevier B.V. All rights reserved.

\section{Introduction}

Trace elements are chemical elements that accumulate in a particular sample or environment in concentrations inferior to $100 \mu \mathrm{g} / \mathrm{g}$ [1]. These elements can be essential or non essential to the living organism. Determining the elemental constitution of mineralized human remains, such as bones, can give information about ante-mortem and post-mortem exposure $[2,3]$.

Human bones are dynamic organs that remodel throughout life

\footnotetext{
* Corresponding author at: Laboratory of Inorganic and Nuclear Chemistry, Wadsworth Center, New York State Department of Health, P.O. Box 509, Albany, NY 12201-0509, USA; diana.guimaraes@health.ny.gov

E-mail address: diana.guimaraes@health.ny.gov (D. Guimarães).
}

and can be differentiated based on their structure. At a macroscopic level we can distinguish between cortical bone: compact, constituting the external bone surface, conferring their strength, rigidity and shape; and trabecular bone: spongy, making up the interior of bones, very porous, more vascular and metabolically active than compact bones. It is estimated that, in adults, about of $5-10 \%$ of the skeleton is replaced per year, with a higher bone turnover for trabecular compared to cortical $[4,5]$. Consequently, depending on in vivo uptake of food and water and environmental exposure, new minerals are continuously being integrated into newly formed bone [6]. Analyzing the elemental constitution of ancient bones can lead to important conclusions on populations' socioeconomic status, occupational practices and even dietary habits [7-9]. Zinc, Sr, and $\mathrm{Br}$ in bone are well established as dietary 
indicators. $\mathrm{Sr}$ is associated with plant intake, with herbivores species showing the highest level of this element [10]. Strontium is also often reported as linked to seafood consumption $[8,11]$ but there some authors that refute that premise [12]. A positive correlation between the $\mathrm{Zn}$ accumulated in bones and the consumption of animal foods high in protein (red meat and birds) as been described $[10,11,13]$. Br levels in the human organism are mainly from a marine diet $[11,14]$. Other elements like Ca, P, O and $\mathrm{H}$ are major constituents of bone mineral content, also known as hydroxapatite [4]. Elements like $\mathrm{Fe}, \mathrm{Cu}$ and $\mathrm{Pb}$ are frequently found in bone. While $\mathrm{Fe}$ and $\mathrm{Cu}$ are essential elements and play a role on bone metabolism [15,16] $\mathrm{Pb}$ is a toxic contaminant [15,17].

Although bone is a good biomarker, its sparse morphological composition makes it prune to post-mortem contamination, also known as diagenesis, particularly in the spongy bone, in part due to its higher surface area $[13,18]$. The burial soil (elemental composition and $\mathrm{pH}$ ) and the weather and environmental conditions (rain, ground water, erosion) play a crucial role in diagenesis, affecting the elemental concentration of the buried bones [8].

Energy Dispersive X-ray Fluorescence (EDXRF) technique is a widespread fully matured instrumental analytical method. It plays an important role in biological samples analysis providing non-destructive multi-elemental analysis, for all the elements with atomic number higher than 13 (or even less in vacuum), in a wide range of concentrations[19]. Due to the minor sample preparation EDXRF has the advantage of being a fast technique at relatively low costs. Since the 1960s XRF has been implemented in archaeological studies [20] being widely used to determine the concentration of trace elements in human bone remains $[8,11,21-23]$ and even to distinguish between human bone and dental remains from other material [24]. EDXRF has also been used to map the spatial distribution of several elements in bone, once it is advantageous over other destructive techniques as laser ablation - inductively coupled plasma - mass spectrometry (LA-ICP-MS) [22,25,26].

In this work the elemental composition of human bone remains (XVIIIth-XIXth century) is measured by energy dispersive X-ray fluorescence (EDXRF). Two complementary setups were used to measure the bones: EDXRF with triaxial geometry and $\mu$-EDXRF with conventional geometry. The first technique allows improved detection limits and the second allows micro beam analysis enabling mapping and spatial distribution of elements within the bone.

The analyzed bones belonged to a group of skeletons recovered from the chapel Ermida do Espirito Santo (EES) in Almada (Portugal), that was built in the XV century [27]. After the big Lisbon earthquake in 1755 that was followed by a tsunami, the chapel started being used as the parish seat, becoming a burial space up to 1833 . At this time burials in churches became forbidden by royal decree, which forced inhumations to be in open space cemeteries. The recent restructuring of the area, promoted by the Municipality, allowed full archaeological intervention of the abandoned chapel. Following the work carried out between 2010 and 2011, human remains of 83 individuals have been exhumed [28], of which 13 will be the subject of the present work. Everything indicates that they remained untouched after death, because they were all oriented on the same way, Southwest-Northeast, according to the ritual of the Catholic Church [29]. The scrapings of the burial shrouds covering two individuals were also analyzed.

\section{Materials and methods}

\subsection{Samples}

\subsubsection{Collection and cleaning}

A total of 30 bones from 13 individuals, dating from XVIIIthXIXth centuries, were recovered from inside a chapel (EES). This collection of skeletons was randomly distributed and in an overall good state of preservation around $1 \mathrm{~m}$ deep, in a very acid soil near the Tagus river in Almada, Portugal. From each individual 2-3 bones were collected (Table 1). Priority was given on having both cortical and trabecular bone parts for each individual but it was not always possible.

All the bones were rinsed in tap water, swept with a brush in order to remove the soil dust and finally washed in distilled water After this, the bones were air dried at room temperature in a clean environment.

It was possible to have access to two burial shrouds' found wrapping the bodies. These samples (from individual \#32 and \#37) were collected and dusted with a brush.

\subsubsection{Preparation for Tri-axial EDXRF analysis}

For each bone, a few grams were taken with a polyester tool (Retsch $\mathrm{GmbH}$, Germany). Due to the poor preservation state of some bones, the use of a mortar and pestle was enough to reduce them to powder. For the more intact bones the samples were powdered in a polyester mill (Retsch $\mathrm{GmbH}$, Germany). In both cases the resulting bone powder was pressed into pellets $15 \mathrm{~mm}$ in diameter, by a $10 \mathrm{t}$ manual hydraulic press from Specac. There was no further chemical treatment or additive to the samples.

For each bone $\mathrm{n}=9$ pellets were made to minimize effects of inhomogeneity. Each pellet, with a thickness of about $1 \mathrm{~mm}$, was glued (heptane mixture) on a Mylar film, fixed into a slide mount and placed on the sample holder $(50 \mathrm{~mm} \times 50 \mathrm{~mm}$ ) in front of the $\mathrm{X}$-ray beam for the element determination.

The remains of two burial shrouds were also analyzed by this instrument but no further treatment was needed, a small piece was placed in front of the beam and the X-ray spectrum was obtained.

Table 1

List of the individuals and bones collected from the chapel Ermida do Espírito Santo and analyzed in this work.

\begin{tabular}{|c|c|c|}
\hline Individual & Bone anatomy & Bone structure \\
\hline \multirow[t]{2}{*}{$\# 1$} & Fibula & Compact \\
\hline & Ribs & Trabecular \\
\hline \multirow[t]{2}{*}{$\# 4$} & Tibia & Compact \\
\hline & Ribs & Trabecular \\
\hline \multirow[t]{3}{*}{ \#6 } & Humerus & Compact \\
\hline & Ribs & Trabecular \\
\hline & Scapula & Compact \\
\hline \multirow[t]{2}{*}{ \#7 } & Humerus & Trabecular \\
\hline & Ribs & Trabecular \\
\hline \multirow[t]{2}{*}{ \#8 } & Femur & Compact \\
\hline & Ribs & Trabecular \\
\hline \multirow[t]{3}{*}{ \#10 } & Fibula & Trabecular \\
\hline & Tibia & Compact \\
\hline & Humerus & Compact \\
\hline \multirow[t]{2}{*}{ \#11 } & Femur & Compact \\
\hline & Ribs & Compact \\
\hline \multirow[t]{2}{*}{ \#14 } & Humerus & Compact \\
\hline & Ribs & Trabecular \\
\hline \multirow[t]{3}{*}{ \#15 } & Ulna & Trabecular \\
\hline & Ribs & Trabecular \\
\hline & Radius & Trabecular \\
\hline \multirow[t]{3}{*}{ \#17 } & Ulna & Trabecular \\
\hline & Ribs & Trabecular \\
\hline & Radius & Compact \\
\hline \multirow[t]{2}{*}{ \#32 } & Radius & Compact \\
\hline & Ribs & Trabecular \\
\hline \multirow[t]{3}{*}{ \#37 } & Tibia & Compact \\
\hline & Fibula & Trabecular \\
\hline & Femur & Trabecular \\
\hline \multirow[t]{2}{*}{ \#83 } & Ulna & Compact \\
\hline & Ribs & Trabecular \\
\hline
\end{tabular}




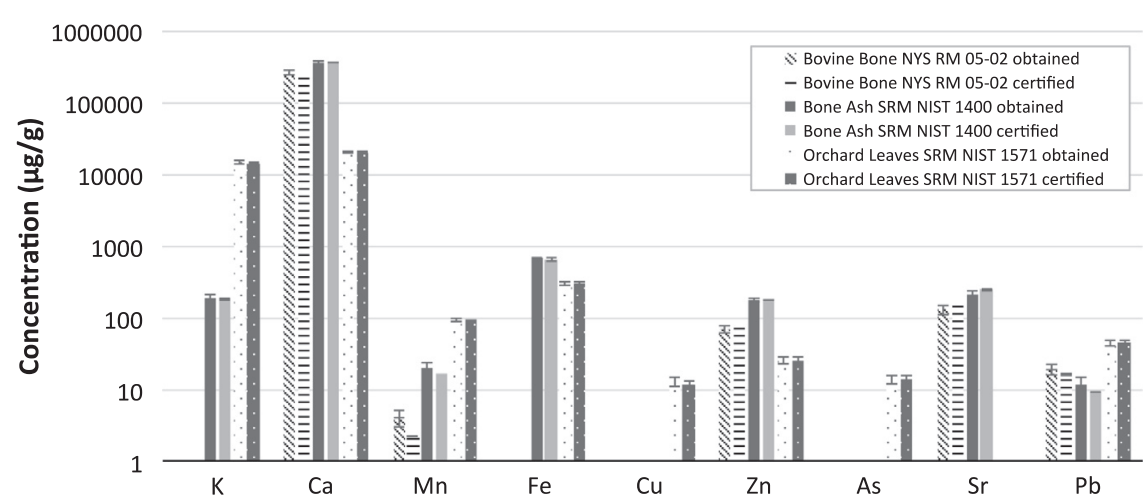

Fig. 1. Triaxial XRF analysis of various biological CRMs.

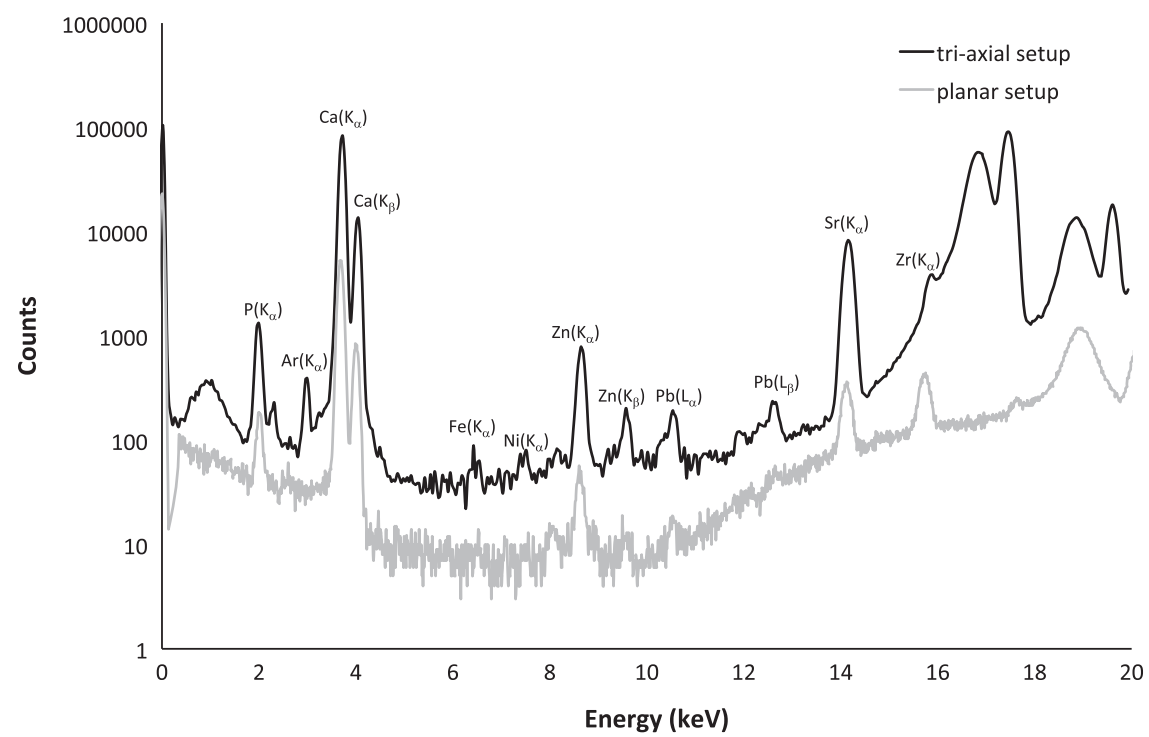

Fig. 2. Spectra obtained by the tri-axial and the $\mu$-XRF instrument when measuring Bovine Bone NYS RM 05-02.

2.1.3. Preparation for $\mu$-EDXRF analysis. For the bones of interest transversal sections, around $1 \mathrm{~mm}$ thick, were obtained using a microtome equipped with a diamond saw (Buehler Isomet 1000, USA). The resulting sample slice would then be placed inside the XRF chamber on a table attached to a XY translatable stage and directly exposed to the X-ray microbeam to perform the elemental mappings. For each bone of interest one map was acquired.

\section{Instrumentation}

\subsection{Tri-axial geometry EDXRF}

A self-constructed spectrometer was used to analyze all the samples. It consists of a commercial X-ray tube with a W anode (Philips PW 2184) operated at $50 \mathrm{kV}$ and $20 \mathrm{~mA}$. A Mo secondary target was placed at a $90^{\circ}$ angle with the sample. With this triaxial arrangement the bremsstrahlung radiation from the X-ray tube anode excites the characteristic lines of the secondary target ( $17.44 \mathrm{keV}$ for $K_{\alpha}, 19.60 \mathrm{keV}$ for $K_{\beta}$ ), which will irradiate the sample. The use of a triaxial geometry, a silver filter and two collimators provide a decrease in the scattering and background radiation [19].

The spot size is ellipse shaped with a major axis of about $2 \mathrm{~cm}$ and a minor axis of about $1.5 \mathrm{~cm}$. This system uses a nitrogencooled $\mathrm{Si}(\mathrm{Li})$ detector by Oxford Instruments (England) with energy resolution of $135 \mathrm{eV}$ at $5.9 \mathrm{keV}$. The acquisition live time per measurement is $1000 \mathrm{~s}$. The concentrations were calculated by our personal software XRFAES (X-ray Fluorescence Automatic Evaluation System) and the quantification method is the Fundamental Parameters method $[19,30]$. In this software, the sample mass is obtained through the information in the coherent and incoherent scattered radiation with a normalizing condition, which means that all concentrations within the sample should add up to unity. The self-attenuation factor is obtained iteratively by constructing a three element virtual matrix that represents the sample. In the present study the chosen matrix was $\mathrm{Ca}, \mathrm{C}$ and $\mathrm{O}$ for the bone samples and $\mathrm{C}, \mathrm{H}, \mathrm{O}$ for the burial shrouds.

\subsection{Conventional geometry $\mu-E D X R F$}

A commercial instrument, the M4 TORNADO (Bruker, Germany) was used for elemental mapping on the cross sections of the more interesting bones. This instrument consists on a low power X-ray tube with a Rh anode and was operated at $50 \mathrm{kV}$ and $300 \mathrm{uA}$. Placed after the X-ray tube, a poly-capillary lens focus the beam to a spot size that can go down to $25 \mu \mathrm{m}$ for Mo-K $\alpha$. The use of filters $(100 \mu \mathrm{m} \mathrm{Al}, 50 \mu \mathrm{m} \mathrm{Ti}$ and $25 \mu \mathrm{m}$ Cu filters) contributes to almost eliminate radiation below $9 \mathrm{keV}$. This, together with the use of the poly-capillary allows a quasi-monochromatic beam between 9 and $15 \mathrm{keV}$ to irradiate the sample. This system uses a thermoelectrically cooled Silicon-Drift-Detector with energy resolution of $142 \mathrm{eV}$ at $5.9 \mathrm{keV}$. The measurements were done under $20 \mathrm{mbar}$ vacuum conditions (to improve detection limits), with a scanning spatial resolution of $25 \mu \mathrm{m}$, with an acquisition live time per measurement of $3.76 \mathrm{~s}$ for each point. In general the maps took 
Table 2

Results obtained by triaxial XRF $(n=9$, mean \pm SD) for Ca and $\mathrm{Sr}$ in 30 buried human bones from 13 different individuals; bold indicates compact bone and nonbold spongy bone.

\begin{tabular}{|c|c|c|c|}
\hline \multirow[t]{2}{*}{ Individual } & \multirow[t]{2}{*}{ Bone } & \multicolumn{2}{|l|}{ Elements } \\
\hline & & $\mathrm{Ca}(\mathrm{wt} \%)$ & $\mathrm{Sr}(\mu \mathrm{g} / \mathrm{g})$ \\
\hline \multirow[t]{2}{*}{$\# 1$} & Fibula & $33 \pm 3$ & $130 \pm 10$ \\
\hline & Ribs & $37 \pm 3$ & $150 \pm 10$ \\
\hline \multirow[t]{2}{*}{$\# 4$} & Tibia & $33 \pm 3$ & $190 \pm 20$ \\
\hline & Ribs & $32 \pm 3$ & $180 \pm 20$ \\
\hline \multirow[t]{2}{*}{ \#6 } & Humerus & $28 \pm 2$ & $190 \pm 20$ \\
\hline & Scapula & $38 \pm 3$ & $200 \pm 20$ \\
\hline \multirow[t]{2}{*}{ \#7 } & Humerus & $32 \pm 3$ & $190 \pm 20$ \\
\hline & Ribs & $35 \pm 3$ & $210 \pm 20$ \\
\hline \multirow[t]{2}{*}{ \#8 } & Femur & $34 \pm 3$ & $170 \pm 10$ \\
\hline & Ribs & $30 \pm 2$ & $170 \pm 10$ \\
\hline \multirow[t]{3}{*}{ \#10 } & Fibula & $34 \pm 3$ & $240 \pm 20$ \\
\hline & Tibia & $33 \pm 3$ & $250 \pm 20$ \\
\hline & Humerus & $27 \pm 2$ & $130 \pm 10$ \\
\hline \multirow[t]{2}{*}{ \#11 } & Femur & $30 \pm 2$ & $200 \pm 20$ \\
\hline & Ribs & $34 \pm 3$ & $230 \pm 20$ \\
\hline \multirow[t]{2}{*}{ \#14 } & Humerus & $33 \pm 3$ & $220 \pm 20$ \\
\hline & Ribs & $35 \pm 3$ & $210 \pm 20$ \\
\hline \multirow[t]{3}{*}{ \#15 } & Ulna & $37 \pm 3$ & $220 \pm 20$ \\
\hline & Ribs & $34 \pm 3$ & $220 \pm 20$ \\
\hline & Radius & $33 \pm 3$ & $220 \pm 20$ \\
\hline \multirow[t]{3}{*}{ \#17 } & Ulna & $37 \pm 3$ & $180 \pm 10$ \\
\hline & Ribs & $38 \pm 3$ & $210 \pm 20$ \\
\hline & Radius & $36 \pm 3$ & $200 \pm 20$ \\
\hline \multirow[t]{2}{*}{ \#32 } & Radius & $36 \pm 3$ & $270 \pm 20$ \\
\hline & Ribs & $33 \pm 3$ & $250 \pm 20$ \\
\hline \multirow[t]{3}{*}{ \#37 } & Tibia & $34 \pm 3$ & $200 \pm 20$ \\
\hline & Fibula & $37 \pm 3$ & $230 \pm 20$ \\
\hline & Femur & $33 \pm 3$ & $230 \pm 20$ \\
\hline \multirow[t]{2}{*}{ \#83 } & Ulna & $32 \pm 3$ & $170 \pm 10$ \\
\hline & Ribs & $35 \pm 3$ & $200 \pm 20$ \\
\hline
\end{tabular}

about $3 \mathrm{~h}$ to ensure high resolution 2D maps for each element.

\section{Statistical analysis}

In this study a multivariate statistical analysis of the data was performed. In particular, the Hierarchical Cluster Analysis (HCA) was used as statistical techniques on a data set of 30 bones and 5 variables (the concentration values for $\mathrm{Fe}, \mathrm{Cu}, \mathrm{Zn}, \mathrm{Br}$ and $\mathrm{Pb}$ ).

The HCA method is a statistical treatment designed to reveal groupings (or clusters) within a data set that could be not evident by the reading of data table. The purpose of this analysis is to join together objects into successively larger clusters, by using some measure of similarity or dissimilarities.

Distance is the basic criterion for any clustering and probably the most straightforward way of computing the distances among objects in a multidimensional space is to compute Euclidean distances. Objects that are near each other should belong to the same cluster, and objects that are far from each other should belong to different clusters. The dendrogram is the graphical summary of the cluster analysis. The cases (or the variables) are listed along the horizontal axis, while the distance among the clusters is showed along the vertical axis.

The agglomerative hierarchical cluster analysis dendrogram was obtained using Microsoft $^{\circledR}$ Excel 2011/XLSTAT ${ }^{\circledR}$-(Version 2015.5.01.23264). The distance between the clusters was defined using the single linkage method with center and reduce to avoid scaling effects. This statistical analysis allows classifying the different bones into groups, or clusters, being the association between different bones strong within cluster and weak between clusters.

\section{Results and discussion}

\subsection{Accuracy and detection limits}

The accuracy and detection limits for these two instruments have already been described in our previous works $[8,9,31]$. Briefly, the tri-axial EDXRF instrument is more precise and accurate than the $\mu$-EDXRF, with accuracy for most of the elements within the uncertainty of the certified/reference value. The accuracy for the triaxial instrument was assessed using bone reference materials (Bone Ash SRM NIST-1400 and Bovine Bone 05-02-Department of Health, New York State, USA) and Orchard Leaves SRM NIST 1571. The results are shown in Fig. 1. Detection limits are also improved for the tri-axial system, and can differ up to one order of magnitude for lighter elements (see Fig. 2) [8].

\subsection{Bone analysis}

\subsubsection{Elemental concentrations by Tri-axial EDXRF}

Using the tri-axial spectrometer all the 30 bones shown in Table 1 (belonging to 13 different individuals) were analyzed including trabecular and cortical regions for each individual, when possible. $\mathrm{Ca}, \mathrm{Zn}, \mathrm{Fe}, \mathrm{Cu}, \mathrm{Br}, \mathrm{Pb}$ and $\mathrm{Sr}$ mean elemental concentrations were obtained and the results are presented in Table 2 and Fig. 3. The error affecting the measurements represents the standard deviation for each sample ( $n=9$ pellets). The results were separated in a table and a figure because when analyzing the data it was possible to identify immediately two distinct behaviors: elements that maintained a similar concentration across the different bones and elements that did not.

Belonging to the former group, $\mathrm{Ca}$ and $\mathrm{Sr}$ (Table 2), have a moderately constant concentration independently of being a spongy bone or a compact bone, from the same or from a different individual. While $\mathrm{Ca}$ is a major essential element of the bone composition, $\mathrm{Sr}$ is a non-essential trace element that competes to replace $\mathrm{Ca}[32,33]$ and has been linked to food consumption habits.

According to Table 2, Ca is the most stable element with relative standard deviations (RSD) of 7\% followed by Sr with a RSD of $16 \%$, across the 30 bones. The values obtained range from 27 to $38 \%$ dry wt for Ca and from 130 to $270 \mu \mathrm{g} / \mathrm{g}$ for Sr. Although the concentration range for $\mathrm{Sr}$ is broad, this is only due to 3 out of 30 bones: compact fibula of individual \#1 $(130 \mu \mathrm{g} / \mathrm{g})$, compact humerus of individual \#10 (130 $\mu \mathrm{g} / \mathrm{g})$ and compact radius of individual \#32 $(270 \mu \mathrm{g} / \mathrm{g})$. Other than that, all other values are within $25 \%$ of the mean value, confirming the constant behavior of this element across all bones. The concentrations obtained for Ca and $\mathrm{Sr}$ are comparable to the values found in human bones determined by other authors $[8,13,34,35]$. Yet, it is important to state that establishing a precise comparison with other studies is extremely difficult because there may be diversity on the type of bones analyzed; cortical vs trabecular; different sample preparation methods (concentrations presented as dry, wet, ash weight, or sometimes not specified); and particular health conditions specific to each individual.

The second group features the elements $\mathrm{Fe}, \mathrm{Zn}, \mathrm{Br}, \mathrm{Cu}$, and $\mathrm{Pb}$, and the results are presented in Fig. 3. These elements do not present homogeneous concentration levels across all bones and reported values are often found outside $30 \%$ of the average value (dashed line in Fig. 3). Additionally, the minimum \%RSD across all the 30 bones is $58 \%$ (for $\mathrm{Br}$ ) but it can go up to $158 \%$ (for $\mathrm{Cu}$ ), showing clearly the variability of $\mathrm{Fe}, \mathrm{Zn}, \mathrm{Br}, \mathrm{Cu}$, and $\mathrm{Pb}$ on this set of bones.

From these 5 elements, only for Fe there is a clear distinction between cortical and trabecular bones. For each individual (with the exception of individual \#14, Fig. 3), it is noticed enrichment in 

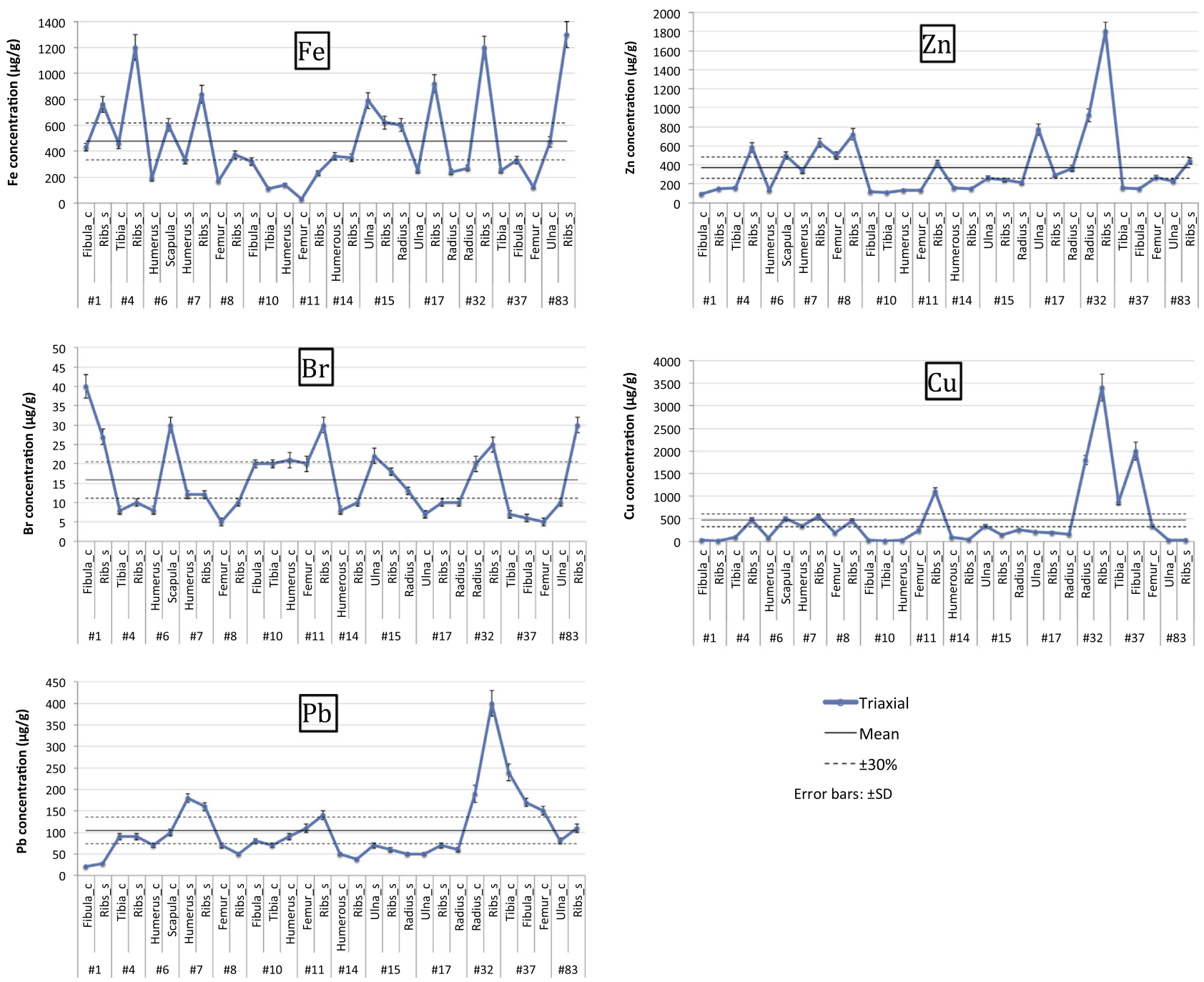

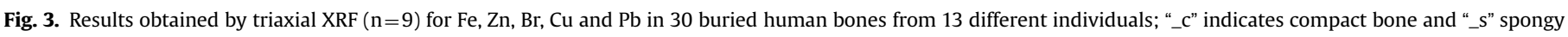
bone.

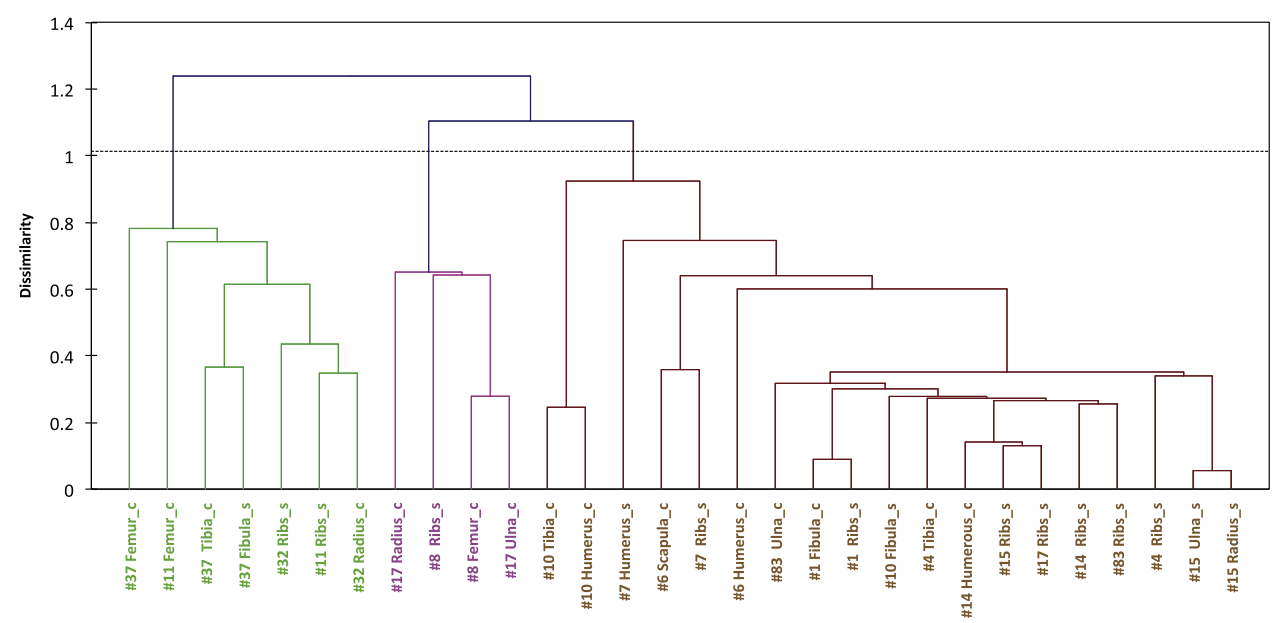

Fig. 4. Dendrogram of the hierarchical cluster analysis for 5 variables ( $\mathrm{Fe}, \mathrm{Cu}, \mathrm{Zn}, \mathrm{Br}$ and $\mathrm{Pb}$ ) using Single Linkage Euclidean distances.

the spongy bones comparing to the compact bones, in particular for the ribs that can go up to a 4-fold increase in individuals \#17 and \#32. Because the spongy tissue is porous and with larger voids it is more susceptible to Fe accumulation, probably due to exchange mechanism between archaeological bone and its surroundings. This is not unexpected and has been reported in other works $[13,36]$. In fact when comparing the range of average concentrations obtained for Fe in this work, with what is reported for contemporary citizens, less than $200 \mu \mathrm{g} / \mathrm{g}$ [35,37,38], the former are (with few exceptions) higher, supporting the likelihood of contamination post-mortem.

Zinc in bone, known as a dietary marker, is usually described as 

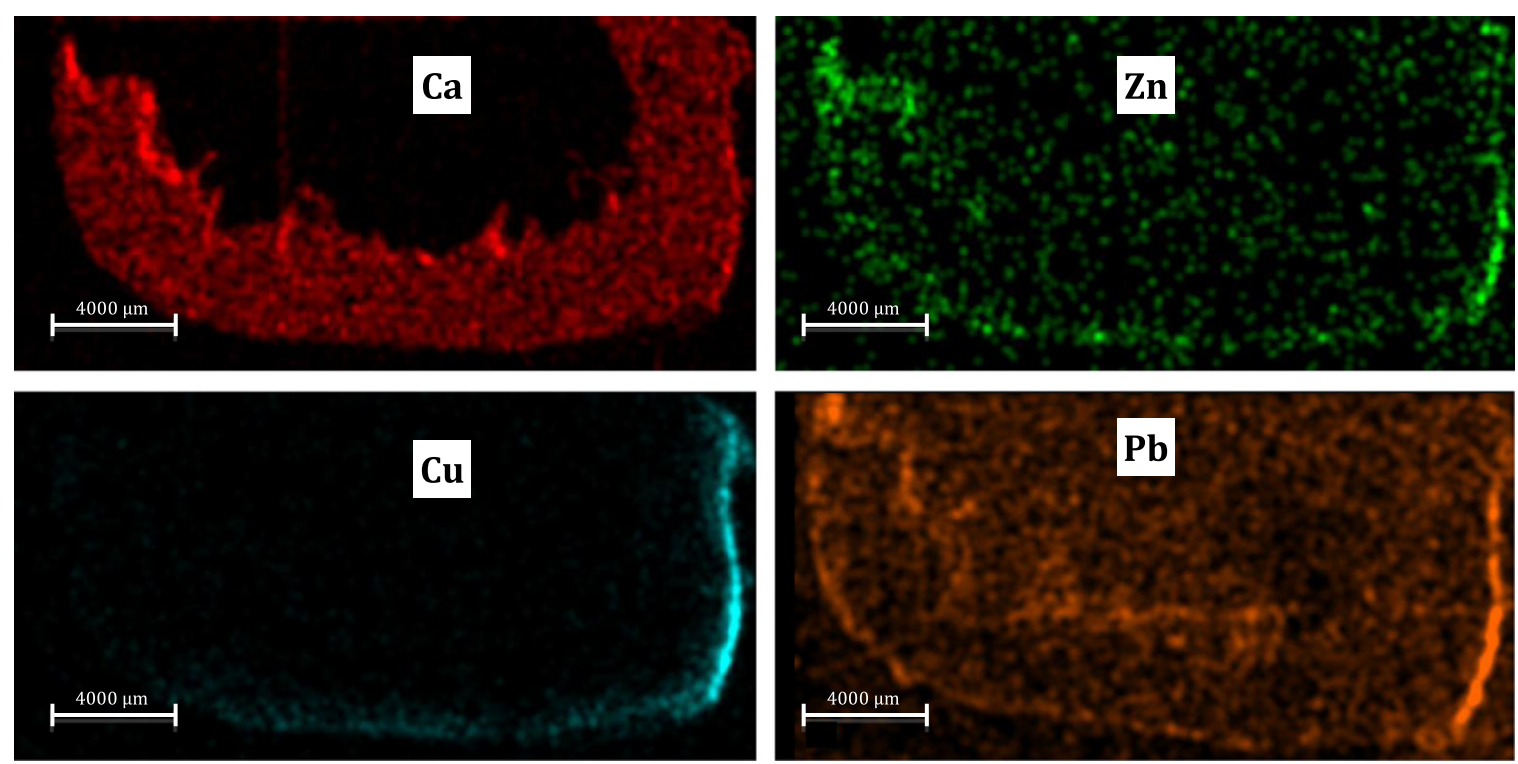

Fig. 5. Calcium, zinc, copper and lead mapping obtained using the $\mu$-EDXRF system for a humerus transversal cross section of individual \#32.
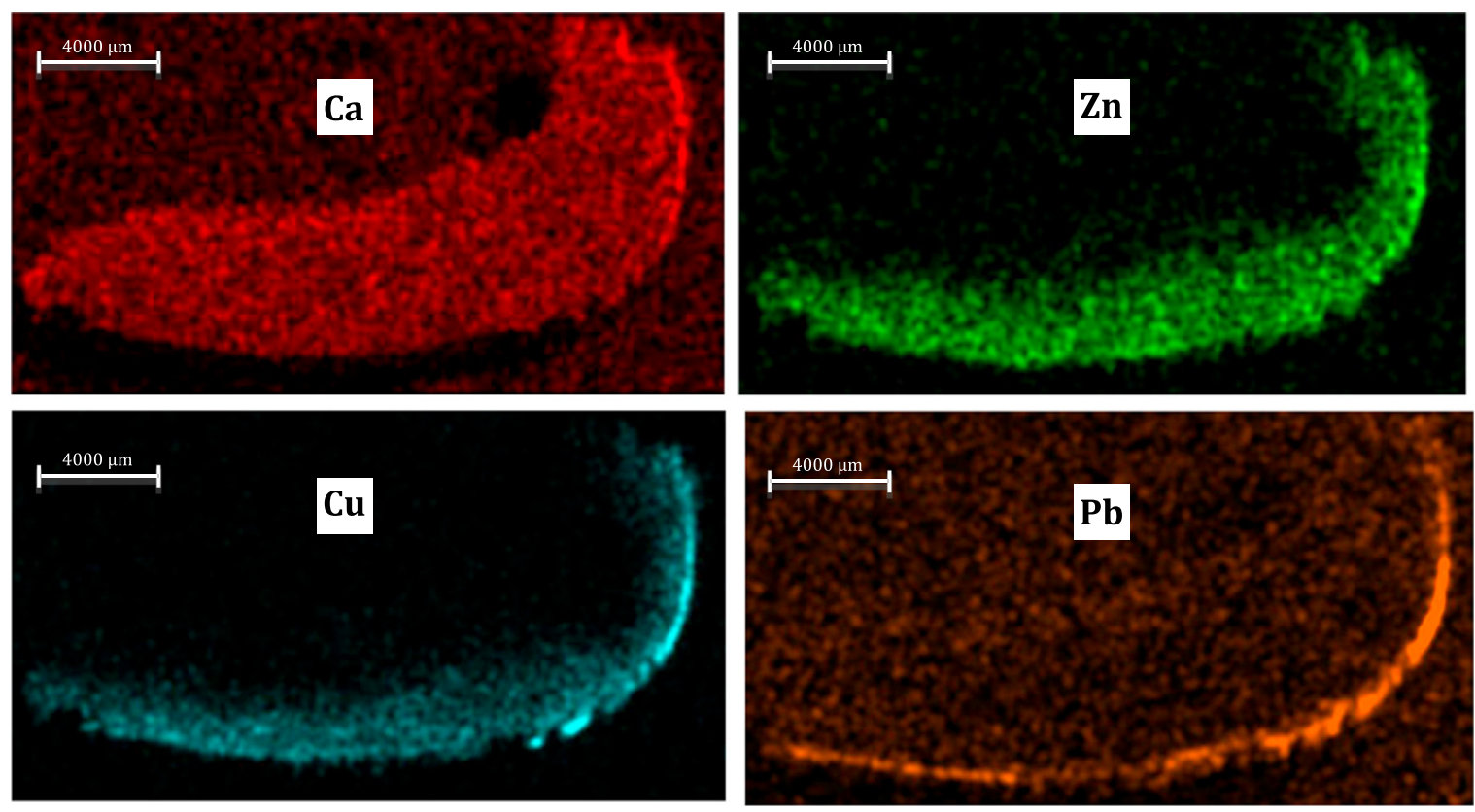

Fig. 6. Calcium, zinc, copper and lead mapping obtained using the $\mu$-EDXRF system for a tibia transversal cross section of individual \#37.

not influenced by diagenesis informing about bone ante-mortem conditions $[10,13]$. However, in the present work, Zinc does not show a steady level (Fig. 3), as stated in other findings $[8,13]$. The results obtained across the 30 bones range from 90 to $1800 \mu \mathrm{g} / \mathrm{g}$ and have a \%RSD of 94, what clearly shows the variability of $\mathrm{Zn}$ concentrations in these samples. With an average value of $371 \mu \mathrm{g} /$ $\mathrm{g}$, the results obtained are higher than what is reported by other studies done in contemporary bones $[2,35,37,38]$. In particular, individual \#32, with $\mathrm{Zn}$ concentration of $1800 \mu \mathrm{g} / \mathrm{g}$ in the spongy part of the ribs, warrants further investigation. It is important to notice that although not frequently linked to post-mortem contamination Elliot and Grime [39], attribute $\mathrm{Zn}$ concentration values found in bone to contamination from burial ground.

Fig. 3 shows enhanced levels of $\mathrm{Br}$ in these samples ranging from 5 to $40 \mu \mathrm{g} / \mathrm{g}$. There is a lack of studies reporting $\mathrm{Br}$ in bone, because it is not always present in significant quantities in the calcified bone mineral. Some studies reporting values of $\mathrm{Br}$ sound in human bone, link it to environmental influence, as marine surroundings, and therefore seafood consumption habits, or nuts $[11,14]$. As mentioned before, the chapel is located near the River Tagus as well as less than $10 \mathrm{~km}$ away from the Atlantic Ocean. Fishery has been the major source of sustenance on this part of the country, what corroborates with the finding of high $\mathrm{Br}$ concentrations.

Copper and $\mathrm{Pb}$ measurements (Fig. 3) also show enhanced levels of these elements across all the 30 bones. With concentrations ranging from 13 to $3400 \mu \mathrm{g} / \mathrm{g}$ for $\mathrm{Cu}$ and 20 to $400 \mu \mathrm{g} / \mathrm{g}$ for $\mathrm{Pb}$, the results are in general higher than the concentrations found in other studies, independently of the sample being ancient bones $[8,11,13,36]$ or contemporary bones $[2,35,37]$. For example Darrah et al. [37] report bone concentrations of $\mathrm{Cu}$ and $\mathrm{Pb}$ found in 58 Rochester residents as ranging from 0 to $31.8 \mu \mathrm{g} / \mathrm{g}$ for $\mathrm{Cu}$ and $<1$ to $9.5 \mu \mathrm{g} / \mathrm{g}$ for $\mathrm{Pb}$. The fact that all these bones, from 13 different individuals, have high levels of $\mathrm{Cu}$ and $\mathrm{Pb}$ suggest, at same extent, 
a)
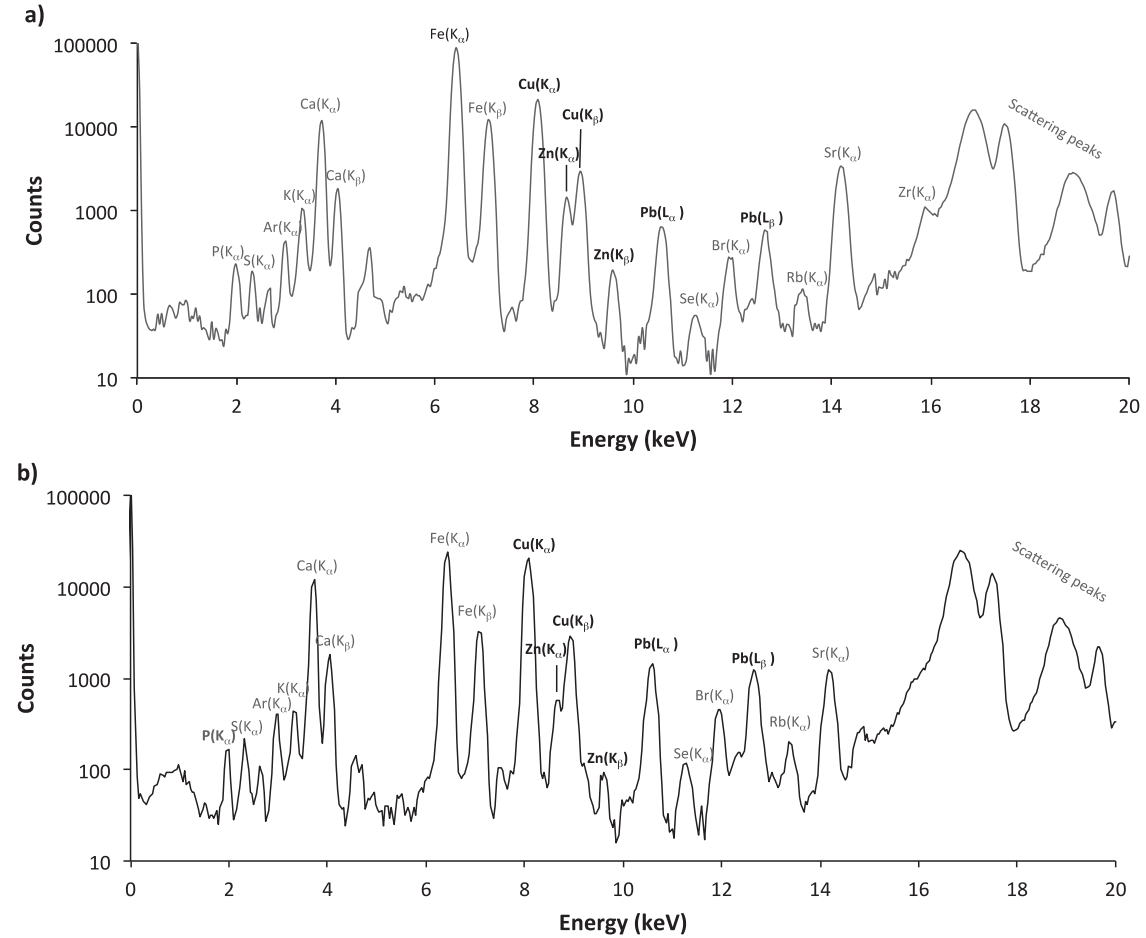

Fig. 7. Burial shrouds spectra obtained using tri-axial EDXRF system. (a) shroud from individual \#32 (b) shroud from individual \#37.

contamination due $\mathrm{Cu}$ and $\mathrm{Pb}$ present in burial soil. However it might not explain all the results. In fact, for individuals \#32 and \#37 $\mathrm{Pb}$ and $\mathrm{Cu}$ concentrations are drastically increased over the other 11 individuals. To better explain these results elemental mapping of the bones of these two individuals is warranted.

\subsubsection{Statistical analysis}

To support the elemental concentration data discussion and to ensure that the large number of analyzed bones is not covering any similarities impossible to detect without statistical analysis, an agglomerative hierarchical cluster analysis was performed. The dendrogram shown in Fig. 4 was constructed using the elemental concentration of the elements that are variable across the 30 bones: $\mathrm{Fe}, \mathrm{Zn}, \mathrm{Br}, \mathrm{Cu}$, and $\mathrm{Pb}$. According to this dendrogram the 30 bones are grouped in three separate clusters, with different sizes. The first group comprehends all the bones from individuals \#32, \#37 and \#11. As seen before individuals \#32 and \#37 were already pointed out as specific cases that needed further investigation, but not individual \#11. Unfortunately the bones from the latter individual were no longer available for further investigation. The second group is the smaller and includes all the bones from individual \#8 and the compact bones of individual \#17. According to Fig. 3, it is possible to determine that all these bones have concentrations lower than the average across all bones for the elements $\mathrm{Fe}, \mathrm{Br}, \mathrm{Cu}$ and $\mathrm{Pb}$. The ribs of individual \#17 were probably out of the cluster due to its high Fe content of $920 \mu \mathrm{g} / \mathrm{g}$. The third group is the biggest and contains all the other bones, with the strongest associations belonging to bones of the same individual as can be seen between fibula and ribs of individual \#1 and ulna and radius of individual \#15. Eventually the second and the third group will merge into an unique cluster at higher distances, with the samples of the first cluster standing out of the rest of the bones. The way the samples were grouped don't show a clear distinction between cortical and trabecular bone.

\subsubsection{Elemental distribution by $\mu-E D X R F$}

In Figs. 5 and 6 are presented the elemental distribution for Ca,
$\mathrm{Zn}, \mathrm{Cu}$ and $\mathrm{Pb}$ in a cross section of humerus from individual \#32 and in a tibia from individual \#37, respectively.

While Ca distribution is uniform in both of the bones, $\mathrm{Zn}$ and $\mathrm{Cu}$ are clearly accumulating in the outer surface. It is evident that the diffusion of these two elements is from the outside to the inner structure of the compact bone, whilst the spongy part remained non-affected. This result suggests that there was contamination post-mortem that might not have been due to exchanges with soil, or it would be seen also in the surface of the endosteal edge. Interestingly both these individuals were wrapped in burial shroud that could be the source of contamination. A fragment of each one of these shrouds was further analyzed.

When comparing the two bones it is noticed that in individual \#37 (Fig. 6) Zn and $\mathrm{Cu}$ penetrate much deeper than in individual \#32 (Fig. 5). Unfortunately it is not possible to use the mappings to determine which bone had higher levels of these elements because the intensity scale is different for each map.

\subsection{Burial shroud analysis}

Burial shroud fragments, covering the remains of individuals \#32 and \#37, were analyzed by the tri-axial instrument and the elements present were identified. According to Fig. 7, it is evident that the shrouds had high levels of $\mathrm{Fe}, \mathrm{Cu}, \mathrm{Zn}$ and $\mathrm{Pb}$. The concentrations measured were 3.2\% Fe, 0.4\% Cu, $215 \mu \mathrm{g} / \mathrm{g} \mathrm{Zn,} 180 \mu \mathrm{g} / \mathrm{g}$ $\mathrm{Pb}$ for the shroud of individual \#32 and $0.5 \% \mathrm{Fe}, 0.3 \% \mathrm{Cu}, 50 \mu \mathrm{g} / \mathrm{g}$ $\mathrm{Zn}$ and $120 \mu \mathrm{g} / \mathrm{g}$ for individual \#37. In fact contamination of human bone remains by the use of shrouds is not unheard of. Archaeological evidence for the use of burial shrouds fastened using copper alloys pins is abundant [40]. In some instances the human bones would even be found with green staining due to the deterioration of the pin with time and consequent contamination of the bone. Whether the elements measured in the shroud were from the shroud fabric itself or from the use of copper alloy pins is not possible to determine, because no pin was found at the burial site. Nonetheless the identification of the shroud as the cause of contamination for the bones of individual \#32 and possibly 
individual \#37 is the most likely explanation.

\section{Conclusion}

In this work human remains from 13 individuals buried in the XVIII-XIXth century were analyzed by two EDXRF instruments: an in-house built tri-axial instrument and a commercial micro X-ray instrument. Measurement of elemental concentrations by the triaxial EDXRF showed that while $\mathrm{Ca}$ and $\mathrm{Sr}$ had steady levels across all the 30 different bones, elements like $\mathrm{Fe}, \mathrm{Zn}, \mathrm{Br}, \mathrm{Cu}$, and $\mathrm{Pb}$ clearly showed variability. Iron and $\mathrm{Br}$ concentrations found in these bones were higher than found by other authors and that was attributed to probably soil contamination and diet (marine surroundings), respectively. Concerning the results for $\mathrm{Zn}, \mathrm{Pb}$ and $\mathrm{Cu}$, they were in average higher than reported in other studies, but two individuals stood out due to their unexpected high concentrations. The imaging of these individuals' bones using a $\mu$-EDXRF instrument based on a polycapillary system showed that these elements were accumulating mainly in the periosteal edge of the bone and that the contamination was clearly post-mortem. In fact both of the individuals were covered in burial shrouds with high concentrations of these elements, accrediting it as the most probable source of contamination.

This work shows how the use of non-destructive X-ray fluorescence techniques can be fit for purpose in the study of biological/archaeological samples. Coupling tri-axial EDXRF with XRF imaging also shows its advantages in respect to assessment about post-mortem vs pre-mortem contamination.

\section{Acknowledgements}

Authors would like to thank Almada Municipality for allowing this investigation.

S. Pessanha acknowledges Portuguese Fundação para a Ciência e Tecnologia for the postdoc grant SFRH/BPD/94234/2013.

\section{References}

[1] Control of preanalytical variation in trace element determinations: Approved Guideline., National Committee for Clinical Laboratory Standards, PA, Wayne, 1997.

[2] M.L. Carvalho, J. Brito, M.A. Barreiros, Study of trace element concentrations in human tissues by EDXRF spectrometry, X-Ray Spectrom. 27 (1998) 198-204.

[3] J. Rebôcho, M.L. Carvalho, A.F. Marques, F.R. Ferreira, D.R. Chettle, Lead postmortem intake in human bones of ancient populations by 109Cd-based X-ray fluorescence and EDXRF, Talanta 70 (2006) 957-961.

[4] U. Kini, B.N. Nandeesh, Physiology of bone formation, remodeling and metabolism, in: I. Fogelman, G. Gnanasegaran, H. VanderWall (Eds.), Radionuclide and Hybrid Bone Imaging, Springer-Verlag, Berlin Heidelberg, 2012, pp. 29-57.

[5] I. Fernández-Tresguerres Hernández-Gil, M.A. Alobera Gracia, Md Canto Pingarrón, L. Blanco Jerez, Bases fisiológicas de la regeneración ósea II: El proceso de remodelado, Med, Oral. Patol, Oral. Y. Cir. Bucal 11 (2006) 151-157.

[6] J. Burton, T.D. Price, The use and abuse of trace elements for paleodietary research, in: S. Ambrose, M.A. Katzenberg (Eds.), Biogeochemical Approaches to Paleodietary Analysis, Springer, US, 2002, pp. 159-171.

[7] L.E. Wittmers, A.C. Aufderheide, J.G. Pounds, K.W. Jones, J.L. Angel, Problems in determination of skeletal lead burden in archaeological samples: an example from the First African Baptist Church population, Am. J. Phys. Anthropol. 136 (2008) 379-386.

[8] M.L. Carvalho, A.F. Marques, Diagenesis evaluation in middle ages human bones using EDXRF, X-Ray Spectrom. 37 (2008) 32-36.

[9] A.A. Dias, M. Carvalho, M.L. Carvalho, S. Pessanha, Quantitative evaluation of ante-mortem lead in human remains of the 18th century by triaxial geometry and bench top micro X-ray fluorescence spectrometry, J. Anal. Atomic Spectrom. 30 (2015) 2488-2495 http://dx.doi.org/10.1039/C5JA00340G10.1039/ C5JA00340G.

[10] I. János, L. Szathmáry, E. Nádas, A. Béni, Z. Dinya, E. Máthé, Evaluation of elemental status of ancient human bone samples from Northeastern Hungary dated to the 10th century AD by XRF, Nucl. Instrum. Methods Phys. Res. Sect. B: Beam Interact. Mater. At. 269 (2011) 2593-2599.
[11] M.L. Carvalho, C. Casaca, T. Pinheiro, J.P. Marques, P. Chevallier, A.S. Cunha, Analysis of human teeth and bones from the chalcolithic period by X-ray spectrometry, Nucl. Instrum. Methods Phys. Res. Sect. B: Beam Interact. Mater. At. 168 (2000) 559-565.

[12] J.H. Burton, T.D. Price, Evaluation of bone strontium as a measure of seafood consumption, Int. J. Osteoarchaeol. 9 (1999) 233-236.

[13] M.L. Carvalho, A.F. Marques, M.T. Lima, U. Reus, Trace elements distribution and post-mortem intake in human bones from middle age by total reflection X-ray fluorescence, Spectrochim. Acta B: . Spectrosc. 59 (2004) 1251-1257.

[14] A.E. Dolphin, S.J. Naftel, A.J. Nelson, R.R. Martin, C.D. White, Bromine in teeth and bone as an indicator of marine diet, J. Archaeol. Sci. 40 (2013) 1778-1786.

[15] J.E. Tahán, V.A. Granadillo, R.A. Romero, Electrothermal atomic absorption spectrometric determination of $\mathrm{Al}, \mathrm{Cu}, \mathrm{Fe}, \mathrm{Pb}, \mathrm{V}$ and $\mathrm{Zn}$ in clinical samples and in certified environmental reference materials, Anal. Chim. Acta 295 (1994) 187-197.

[16] T. Sierpinska, J. Konstantynowicz, K. Orywal, M. Golebiewska, M. Szmitkowski, Copper deficit as a potential pathogenic factor of reduced bone mineral density and severe tooth wear, Osteoporos. Int. 25 (2014) 447-454.

[17] A.C. Todd, S. Carroll, C. Geraghty, F.A. Khan, E.L. Moshier, S. Tang, P.J. Parsons, Lshell X-ray fluorescence measurements of lead in bone: accuracy and precision, Phys. Med. Biol. 47 (2002) 1399-1419.

[18] A. Perrone, J.E. Finlayson, E.J. Bartelink, K.D. Dalton, -Application of portable $\mathrm{X}$-ray fluorescence (XRF) for sorting commingled human remains (Chapter 7) in: B.J.A.E. Byrd (Ed.), Commingled Human Remains, Academic Press, San Diego, 2014, pp. 145-165.

[19] R. Van Grieken, A. Markowicz, Handbook of X-Ray Spectrometry: Methods and Techniques, Marcel Dekker, New York, 1992.

[20] M.S. Shackley, An Introduction to X-Ray Fluorescece (XRF) Analysis in Archaeology, X-Ray Fluorescence Spectrometry (XRF) in Geoarcheology, Springer,, New York 2011, pp. 7-44.

[21] B. Pemmer, A. Roschger, A. Wastl, J.G. Hofstaetter, P. Wobrauschek, R. Simon, H.W. Thaler, P. Roschger, K. Klaushofer, C. Streli, Spatial distribution of the trace elements zinc, strontium and lead in human bone tissue, Bone 57 (2013) 184-193.

[22] N. Zoeger, C. Streli, P. Wobrauschek, C. Jokubonis, G. Pepponi, P. Roschger, J. Hofstaetter, A. Berzlanovich, D. Wegrzynek, E. Chinea-Cano, A. Markowicz, R. Simon, G. Falkenberg, Determination of the elemental distribution in human joint bones by SR micro XRF, X-Ray Spectrom. 37 (2008) 3-11.

[23] G. Piga, A. Santos-Cubedo, S. Moya Solà, A. Brunetti, A. Malgosa, S. Enzo, An $\mathrm{X}$-ray diffraction (XRD) and X-ray Fluorescence (XRF) investigation in human and animal fossil bones from Holocene to Middle Triassic, J. Archaeol. Sci. 36 (2009) 1857-1868

[24] A.M. Christensen, M.A. Smith, R.M. Thomas, Validation of X-ray fluorescence spectrometry for determining osseous or dental origin of unknown material, J. Forensic Sci. 57 (2012) 47-51.

[25] D.J. Bellis, D. Li, Z. Chen, W.M. Gibson, P.J. Parsons, Measurement of the microdistribution of strontium and lead in bone via benchtop monochromatic microbeam X-ray fluorescence with a low power source, J. Anal. . Spectrom. 24 (2009) 622-626.

[26] P. Roschger, I. Manjubala, N. Zoeger, F. Meirer, R. Simon, C. Li, N. Fratzl-Zelman, B.M. Misof, E.P. Paschalis, C. Streli, P. Fratzl, K. Klaushofer, Bone material quality in transiliac bone biopsies of postmenopausal osteoporotic women after 3 years of strontium ranelate treatment, J. Bone Mineral. Res. 25 (2010) 891-900.

[27] T. Antonio, F. Henriques, A Ermida do Espirito Santo de Almada, Camara Municipal de Almada Divisao de Museus e Patrimonio Cultural, 2012, pp. 150 154.

[28] F. Curate, T. Antonio, S. rosa, F. Robles, Fracturas bilaterales de tibia y perone en un individuo femenino de la "Ermida de Espirito Santo. (Almada, Portugal), in: A. Malgosa, A. Isidro, P. Ibanez-Gimeno, G. Prats-Munoz (Eds.) Actas del XI Congreso Nacional DE Paleopatologia, 2013.

[29] F. Curate, F.R. Henriques, S. Rosa, M. Vitor M. J, A. Tavares, T. Antonio, Mortalidade Perinatal na Ermida do Espírito Santo (Almada): Entre o afecto e a marginalização, Al-Madan, Lisboa, Portugal 2015, pp. 68-76.

[30] A. Rindby, Software for energy-dispersive X-ray fluorescence, X-Ray Spectrom. 18 (1989) 113-118.

[31] S. Pessanha, M. Carvalho, M.L. Carvalho, A. Dias, Quantitative analysis of human remains from 18th-19th centuries using X-ray fluorescence techniques: the mysterious high content of mercury in hair, J. Trace Elem. Med. Biol. 33 (2016) 26-30.

[32] A.L. Rheingold, S. Hues, M.N. Cohen, Strontium and zinc content in bones as an indication of diet, J. Chem. Educ. 60 (1983) 233-234.

[33] F. Bronner, Metals in Bone: Aluminum, Boron, Cadmium, Chromium, Lanthanum, Lead, Silicon, and Strontium (Chapter 25), in: J.P.B.G.R.J. Martin (Ed.) Principles of Bone Biology, Third ed.,Academic Press, San Diego, 2008, pp. 515-531.

[34] V. Zaichick, M. Tzaphlidou, Determination of calcium, phosphorus, and the calcium/phosphorus ratio in cortical bone from the human femoral neck by neutron activation analysis, Appl. Radiat. Isot. 56 (2002) 781-786.

[35] H.S. Mahanti, R.M. Barnes, Determination of major, minor and trace element in bone by inductively-coupled plasma emission spectrometry, Anal. Chim. Acta 151 (1983) 409-417.

[36] I. Reiche, L. Favre-Quattropani, T. Calligaro, J. Salomon, H. Bocherens, L. Charlet M. Menu, Trace element composition of archaeological bones and post-mortem alteration in the burial environment, Nucl. Instrum. Methods Phys. Res. Sect. B: Beam Interact. Mater. At. 150 (1999) 656-662. 
[37] T. Darrah, M.E. Campbell, J. Prustman-Pfeiffer, R. Poreda, R. Hannigan, Trace element composition of modern human bone, in: P. Censi, T. Darrah, Y. Erel (Eds.), Medical Geochemistry, Springer, Netherlands, 2013, pp. 167-191.

[38] M.L. Carvalho, A.F. Marques, J. Brito, Synchrotron radiation and energy dispersive $\mathrm{x}$-ray fluorescence applications on elemental distribution in human hair and bones, AIP Conf. Proc. 652 (2003) 522-528.
[39] T.A. Elliott, G.W. Grime, Examining the diagenetic alteration of human bone material from a range of archaeological burial sites using nuclear microscopy, Nucl. Instrum. Methods Phys. Res. Sect. B: Beam Interact. Mater. At. 77 (1993) 537-547.

[40] M. Hall, S.W. Silliman, Historical Archaeology, Blackwell Pub,, Malden, MA, 2006. 